\title{
O movimento do Canto Coral no sistema educativo português da Primeira República ao Estado Novo*
}

\author{
EL MOVIMIENTO DEL CANTO CORAL EN EL SISTEMA EDUCATIVO PORTUGUÉS DE LA PRIMERA \\ REPÚBLICA AL ESTADO NUEVO
}

THE CANTO CORAL MOVEMENT IN THE PORTUGUESE EDUCATION SYSTEM FROM THE FIRST REPUBLIC TO THE NEW STATE

\section{Maria Cristina Aguiar ** Maria Helena Vieira***}

Cuadernos de Música, Artes Visuales y Artes Escénicas

/ Volumen 13- Número 2 / Julio - Diciembre de 2018

/ ISSN 1794-6670/ Bogotá, D.C., Colombia / pp. 189-204

Fecha de recepción: 01 de julio de 2016

Fecha de aceptación: 17 de mayo de 2017

Disponible en línea: 1 de junio de 2018

doi:10.11144/javeriana.mavae13-2.omdc

* $\quad$ Artigo de reflexão. Produto de uma investigação sob a Especialidade de Educação Musical do Programa de Doutoramento em Estudos da Criança da Universidade do Minho, Instituto de Educação - Braga, Portugal. Este trabalho foi financiado por fundos nacionais através da FCT (Fundação para a Ciência e a Tecnologia) e foi co-financiado pelo Fundo Europeu de Desenvolvimento Regional (FEDER) através de COMPETE 2020 - Programa Operacional Competitividade e Internacionalização (POCI).

* Professora da Escola Superior de Educação, Instituto Politécnico de Viseu, Portugal. Mestre em Música pela Universidade de Aveiro, e doutorada em Estudos da Criança, Educação Musical, pela Universidade do Minho, é membro do CIEC (Centro de Investigação em Estudos da Criança) e professora no Conservatório de Música de Viseu. ORCID: 0000-0003-2094-9216

*** Professora do Instituto de Educação da Universidade do Minho (Braga, Portugal). Directora do "Mestrado em Ensino de Música" e membro da direcção do "Programa de Doutoramento em Estudos da Criança" como coordenadora da Especialidade de Educação Artística na mesma universidade. Membro do CIEC (Centro de Investigação em Estudos da Criança). ORCID: 0000-0003-1346-1925 


\section{Resumo}

Neste artigo é feita uma abordagem ao despontar do movimento do Canto Coral no sistema de ensino português, do alvor da Primeira República ao enraizar do Estado Novo. Centrando toda a reflexão ao nível da prática vocal/coral, e salientando a tensão existente entre o caráter progressista das artes e o cariz conservador do Estado Novo, são ainda apresentadas as circunstâncias históricas e sociais que antecederam o ensino à distância. Refere-se o papel da Rádio Escolar e da Telescola na divulgação do ensino da música e da prática vocal. Esta reflexão resulta da realização de um estudo de caso múltiplo centrado no paradigma qualitativo que incidiu na análise da forma como se tem vindo a realizar o ensino de canto em Portugal no $1^{\circ}$ ciclo do ensino básico, genérico e especializado, e que permitiu inferir que o ensino de canto não está ainda generalizado em nenhuma destas vertentes de ensino.

Palavras-chave: Canto Coral; ensino de canto; sistema educativo; reformas educativas; rádio escolar; ensino à distância.

\section{Resumen}

En este artículo se realiza una aproximación al movimiento del Canto Coral en el sistema educativo portugués de la $1^{\text {a }}$ República al Estado Novo. Centrándose la reflexión en el ámbito de la práctica vocal/coral, y destacando la tensión entre el carácter progresivo de las artes y la naturaleza conservadora del Estado Novo, también presenta las circunstancias históricas y sociales que antecederán la enseñanza a distancia. Se refiere el papel del Radio Escolar y Telescola en la difusión de la enseñanza de la música y la práctica vocal. Esta reflexión resulta de la realización de un estudio de casos múltiples centrado en el paradigma cualitativo y enfocado en el análisis de cómo se ha llevado a cabo la enseñanza de canto en Portugal en el 1er ciclo de la educación básica, general y especializada, y que nos permitió inferir que la enseñanza de canto aún no se ha generalizado en cualquiera de estos aspectos educativos.

Palabras clave: Canto Coral; enseñanza de canto; sistema educativo; reformas educativas; radio escolar; enseñanza a distancia

\section{Abstract}

This article focuses on the beginning and development of the movement of Canto Coral in the Portuguese system of education, from the emergence of the First Republic to the period of dictatorship known as Estado Novo ("New State"). The study describes vocal and choral practice during that period and reveals the tension that was occurring between progressive nature of the arts and the New State's inflexibility and conservatism. The historical and social circumstances that preceded distance learning in music are also described. The results presented emerged from a qualitative multiple case study that analysed the evolution of voice teaching in Portugal in the $1 \mathrm{~s}$ cycle (children between the ages of 6 and 9) of generalist and specialized schools. Ultimately, the study allowed the inference that voice teaching is not yet today a reality in neither the generalist nor the specialized branch of music education, although singing activities have been quite frequent.

Keywords: Canto Coral; voice teaching, educational system; educational reforms; school radio; distance learning. 


\section{A PRIMEIRA REPÚBLICA, 0 ESTADO NOVO E O MOVIMENTO DO CANTO CORAL}

A 5 de outubro de 1910, ultrapassado um período conturbado de lutas e conflitos que condiciona a queda da monarquia, Portugal muda de regime político e instaura a Primeira República, iniciando-se uma nova era de desenvolvimento de políticas educativas. Segundo Reis, Magalhães, e Alçada (2010), José Falcão, num dos escritos mais notáveis de propaganda republicana, Cartilha do Povo, viria a afirmar que,

só a educação poderia libertar o povo da ignorância, ajudar a que todos tomassem consciência dos seus direitos e assim elevar o nível de vida das classes mais desfavorecidas. (211)

De acordo com Barreiros (1999), com a instauração do novo regime e

como consequência do pensamento progressista, veiculado pela elite da intelectualidade portuguesa, a educação tornou-se uma prioridade do regime republicano, que se esforçou por combater o analfabetismo, proceder à extensão da educação popular, [e] melhorar a qualidade do ensino. (27)

Foram inúmeras, neste período, as iniciativas para combater o analfabetismo. A grande maioria do povo português não sabia ler nem escrever, apenas por nunca ter tido a possibilidade de frequentar a escola. Antevia-se a necessidade de formação intensiva dos cidadãos, possibilitando a sua transformação em indivíduos com acesso à leitura e à escrita, e com a capacidade de se tornarem eleitores. Segundo Barreiros (1999) e Pimenta (2006), poderá afirmar-se que durante a Primeira República houve uma preocupação bastante cuidada ao nível do ensino, quer relativamente à produção de documentos legislativos de cariz inovador, quer ao nível do próprio pensamento pedagógico; contudo, os ideais republicanos foram depostos e integralmente desconsiderados no preciso momento em que se deu a queda do regime, em 1926, com um golpe de Estado do General Gomes da Costa, que pôs fim à Primeira República.

As reformas do ensino durante o período da Primeira República iniciaram-se ao nível do ensino primário. Embora com data de 29 de março de 1911, era publicado no Diário do Governo $n^{\circ} 73$ de 30 de março de 1911 um decreto que previa a criação do ensino infantil público e que reformulava as bases do ensino primário', dividindo-o em três ciclos de frequência gratuita: primário elementar (obrigatório); primário complementar; e primário superior. Estabelece-se o princípio da escolaridade obrigatória dos sete aos catorze anos, embora circunscrito a alunos cuja residência se situasse num raio de dois quilómetros de uma escola pública ou de uma escola particular gratuita. Não obstante, surgem dificuldades na execução destas medidas, designadamente no que se refere à questão do financiamento. Dois meses mais tarde, a 26 de maio de 1911, é publicado o decreto com força de lei que criava a Instrução Militar Preparatória² ${ }^{2}$ em que o programa do primeiro grau compreendia educação cívica e educação física, esta última envolvendo a vertente musical (Carvalho 1986, 653-654). 
Posteriormente, pelo Decreto 5787-A de 10 de maio de 1919³, o Ministro Leonardo Coimbra empreende uma nova reforma que viria a ficar conhecida como "a Reforma do ensino primário de 1919", a qual vem alargar o ensino obrigatório de dois para cinco anos, mas cujo alcance foi menor do que seria expectável, uma vez mais por condicionalismos económicos e falta de verbas. Esta reforma

não alterou os conteúdos formais de aprendizagem implementados a partir de 1911, mas elevou a duração da escolaridade obrigatória para cinco classes (de frequência universal e gratuita dos 7 aos 12 anos). Uma outra novidade é a adopção do princípio da co-educação dos géneros, dando continuidade à prática instalada no ensino infantil e antecipando a que também organizaria o grau superior do ensino primário. (Correia 2010)

É no período da Primeira República que acontecem algumas modificações no ensino liceal, mais concretamente ao nível do ensino secundário feminino que se havia tornado efetivo em 1906. A 11 de junho de 1915, o Diário do Governo nº 110 divulga a criação de um curso especial de educação feminina, decorrendo paralelamente ao curso do ensino secundário 4 . De acordo com Rocha $(1984,295)$, antecipando uma formação mais completa da mulher, são introduzidas novas disciplinas para além das matérias previstas no plano de estudos do curso geral; entre elas, destaca-se a Música. Três anos mais tarde, através da publicação do Decreto $n^{\circ} 4650$ de 14 de julho de 1918, surgem no ensino liceal as novas disciplinas de Canto Coral e Trabalhos Manuais, denotando a vontade de promover a instrução com vista a uma educação clássica ${ }^{5}$. Segundo Cunha $(2002,234)$, no ensino secundário feminino, o Canto Coral passava a coexistir com lições de piano, embora se mantivessem os planos de estudos gerais do ensino masculino.

Em junho de 1923, por intermédio do Ministro da Instrução, João Camoesas, através do documento "Estatuto da Educação Pública", uma outra reforma chega à Câmara dos Deputados, procurando implementar um plano abrangente para a educação. Esta proposta foi bastante apreciada, uma vez que procurava o fim da visão fragmentada do ensino, optando por uma perspetiva mais alargada e global de todo o sistema educativo. Contudo, a reforma não se efetivou, vítima da queda do governo de Camoesas em novembro do mesmo ano (Carvalho 1986, 697-703).

Portugal, no início do século XX, estava distante da realidade educativa e cultural de diversos países europeus, onde começavam a florescer diversas formações corais. Contudo, durante o período da Primeira República, essa influência chega a Portugal:

De entusiasmo e de solidariedade precisava a jovem República. O canto era por isso elemento que faltava para pôr em comunhão as almas e atingir o estado da grande festa cívica em que os republicanos apostavam transformar as celebrações nacionais. (Dias 2009, 150)

Gera-se, de imediato, uma simpatia generalizada pelo Canto Coral, embora a sua dimensão de carácter moral, cívico e social o mantivesse afastado de uma educação ou orientação especificamente musical:

O canto ficou vinculado à matriz militarista e patriótica, ditada pelo diploma e indirectamente pelo modelo da experiência que lhe estivera na origem - a francesa. (Dias 2009, 151) 
Embora a sua ação não tivesse recebido o apoio generalizado dos professores do ensino artístico, é incontestável o papel de Tomás Borba na introdução do solfejo entoado na Escola Normal Primária, onde era professor, e na expansão do movimento coral um pouco por todo o país, certificando o seu carácter educativo. São vários os livros de exercícios de solfejo que publicou, contribuindo para a afirmação das suas noções pedagógicas tão inovadoras para a época. Segundo o compositor Lopes-Graça (1973),

a obra que, com pertinácia, devoção e inteligência, realizou no domínio do ensino elementar da arte dos sons, que foi a implantação entre nós do chamado solfejo entoado, em oposição ao antiquado, rotineiro e anti-musical solfejo rezado, essa obra não pode deixar de ser credora do maior respeito por parte de quantos se interessam ou preocupam com os problemas da educação. (116)

Várias décadas antes, outro vulto se havia destacado na área do ensino de música especializado. João Domingos Bomtempo, em 1834, desenvolve um projeto de reforma do Ensino da Música em Portugal, do qual ressaltam duas ideias basilares: considerar o ensino que contemplasse a música instrumental e de natureza lírica, e formar músicos e cantores portugueses que viessem a colmatar as carências artísticas do país. Para infelicidade do sistema educativo e cultural português, esta reforma não veio a concretizar-se; contudo, no ano seguinte, em 1835, foi criado um Conservatório de Música, anexo à Casa Pia, que mais tarde viria a ser associado ao Conservatório Geral de Arte Dramática (posteriormente designado por Conservatório Real de Lisboa), o qual se dividia em duas escolas: uma Escola de Música e uma Escola de Teatro e Declamação (que também compreendia uma disciplina de Dança). Com o surgir da Primeira República, em 1910, o conservatório recebe nova designação: Conservatório Nacional de Lisboa.

A veia reformista de alguns vultos ligados ao ensino da música em Portugal levou a que, em 1919, surgisse um conjunto de propostas para a reestruturação do ensino artístico, designado como Reforma de Vianna da Motta, um dos seus mentores. Introduziram-se novas disciplinas (Cultura Geral, Leitura de Partituras e Instrumentação e Regência), foi criada a Classe de Ciências Musicais (com História da Música, Acústica e Estética Musical), desenvolveu-se o Curso de Composição e optou-se, definitivamente, pelo Solfejo Entoado (Aguiar 2007, 32). O preâmbulo do Decreto n 5546 de 9 de maio de 1919 apresenta os argumentos que levaram à concretização da reforma do ensino, considerado antiquado. Atente-se a sistematização de Aguiar relativamente às fundamentações utilizadas:

[as aulas eram] de organização irregular, [...] desinteressantes, agravadas por um ensino individualizado que, por excesso de alunos nas classes, se reduzia a pouco mais de dez minutos mensais, fomentando o ensino paralelo de alunos mais adiantados com alunos de iniciação, apesar de todos os contras que esses hábitos poderão conter; mais ainda, o solfejo rezado era ainda prática efetiva, não se ministrando qualquer preparação prévia relativa a outras "sciências musicais". (Aguiar 2014, 46) 
Ainda no preâmbulo sobressai a divisão dos cursos de Instrumento, de Canto e de Composição em três graus (elementar, complementar e superior), e contempla-se a abertura de cursos livres de instrumento. Relativamente ao Curso de Canto, e após o nível complementar, abrem-se duas vias de estudo: canto teatral e "concêrto".

Assente na crença de que apenas se deve iniciar o trabalho vocal após o desenvolvimento do aparelho fonador (mudança da voz), o artigo $16^{\circ}$ apenas prevê idade mínima de 16 anos para frequentar o Curso de Canto, embora apresente limite máximo de idade de admissão para os cursos restantes. Estabelecer uma idade mínima para o Curso de Canto foi um procedimento que se manteve ao longo de muitas décadas, condicionando o trabalho vocal de crianças e jovens adolescentes. Não obstante, o artigo $6^{\circ}$ do Decreto $n^{\circ} 5546$ vem determinar que as aulas de canto coral passem a ser obrigatórias para todos os alunos, "desde que possuam os requisitos vocais adequados" (789).

Após a reforma de Vianna da Motta, que contribuiu para que aquela época viesse a ser considerada como um dos períodos de excelência do Conservatório Nacional de Música, o ensino entra em colapso. Entre 1919 e 1926, terminada a Primeira Guerra Mundial, agravou-se a situação de insegurança e o clima de incerteza em Portugal. Os problemas de desemprego e as lutas partidárias cedo contribuíram para gerar um clima de desestabilização. Apesar da criação de sindicatos e da conquista de alguma liberdade de expressão, o novo regime parlamentar ficava desde cedo comprometido, levando ao poder vinte e seis governos, alguns dos quais se mantiveram apenas alguns dias.

Em 28 de maio de 1926, é levado a efeito um golpe de Estado que poria fim à Primeira República. Esta ação, liderada por Gomes da Costa e Mendes Cabeçadas, tem como consequência direta a implantação da Ditadura Nacional que, após a aprovação da Constituição de 1933, viria a ser designada por Estado Novo. Esta foi a mais longa ditadura da Europa Ocidental, cujo regime governativo se manteve ininterrupto até ao ano de 1974. De 1932 a 1968, a ação governativa de António de Oliveira Salazar contribuiu para a estagnação do país ao nível de todos os setores, uma vez que se alicerçava em ideais nacionalistas e isolacionistas.

Todas as conceções republicanas foram banidas dos programas educativos. Dominava a mentalidade nacionalista e qualquer pensamento contrário aos ideais do governo era reprimido pela ação das forças políticas. Quando os princípios basilares do regime não eram seguidos fielmente, eram automaticamente acionados mecanismos de censura e de repressão. Segundo Nery e Castro (1991), vivia-se num regime fechado, assente num

movimento de crispação ideológica profundamente adverso a qualquer forma de actividade artística, reforçado ainda pela política de puritanismo moral e austeridade económica de Salazar,

[...] para quem a instrução e a cultura não constituíram nunca prioridade. (165)

De acordo com Pimenta (2006, 31), o único interesse do Estado Novo ao nível da educação era proporcionar a instrução mínima aos cidadãos (ler, escrever e contar); desta forma, e uma vez que a prioridade era diminuir as despesas do Estado, embora o regime possuísse os meios económicos para combater o analfabetismo, nada foi feito nesse sentido. Compreende-se, assim, a redução da escolaridade obrigatória, a restrição do número de disciplinas dos currículos escolares e a desconsideração pela profissão docente, para a qual contribuía o facto de, na grande maioria dos casos, os professores serem contratados pela sua idoneidade moral e intelectual e não pelas suas habilitações. 
Relativamente ao ensino artístico, a 14 de junho de 1930 é publicado o Decreto ${ }^{\circ} 18461^{6}$. Pode ler-se no artigo $1^{\circ}$ que o Conservatório Nacional de Música e o Conservatório Nacional de Teatro passam a formar uma instituição escolar única, designada por Conservatório Nacional. A 25 de setembro do mesmo ano, é publicado o Decreto $n^{\circ} 18881$ que aprova a reorganização do Conservatório Nacional7. Este viria a funcionar sob a gestão de um inspetor da Direcção Geral do Ensino Superior e das Belas Artes, e seria constituído por uma Secção de Música (ensino da música vocal, da música instrumental e da composição) e por uma Secção de Teatro (ensino da arte de dizer, da arte de representar, da coreografia e da "scenografia").

No que se refere ao Curso de Canto, sobressaem algumas alterações de fundo. À totalidade da duração do curso é subtraído um ano e os níveis Elementar e Complementar são incorporados num único escalão, designado por nível Geral. Esta reforma, que na atualidade é ainda referida como a "Reforma de 1930", manteve-se ao longo de muitas décadas; até à entrada em funcionamento do Curso de Canto no Ensino Básico, em 2009, os três anos de canto do Curso Complementar eram o único contacto que os alunos poderiam ter com o ensino, antes da sua ida para o ensino superior.

O Decreto $n^{\circ} 18881$ determina ainda o funcionamento de três classes de conjunto, nomeadamente Canto Coral, Música de Câmara e Orquestra e, no artigo $15^{\circ}$, determina-se a obrigatoriedade do canto coral para todos os alunos, salvo casos especiais devidamente comprovados. Já previstas na Reforma de 1919, as aulas de Canto Coral acabaram por sucumbir

à crescente ideologização do regime. A intenção [do Canto Coral vir a cumprir] [...] uma função educativa é subvalorizada pela tutela que, por essa razão, nunca chega a criar as condições institucionais necessárias à sua real participação e contributo no currículo liceal. (Barreiros 1999, 127- 128)

Aos poucos, o canto começa a ser aceite em atividades de caráter social, embora o trabalho vocal seja colocado em segundo plano, relativamente ao objetivo principal de veicular a mensagem do texto patriótico.

Algumas disciplinas foram retiradas do currículo da Escola de Música do Conservatório Nacional devido a cortes orçamentais e a uma visão antiquada do ensino da música, motivos que também contribuíram para enfraquecer os progressos conseguidos com a Reforma de Vianna da Motta.

Após o golpe militar de 1928, as finanças públicas entram em colapso. O preâmbulo do já referenciado Decreto n 18881 assume que a reforma implementada está "longe de determinar aumento da despesa" e assegura que "da execução deste decreto resulta uma sensível economia para o Estado" (1966). Contudo, esta explicação relativa às questões económico-financeiras tem como principal objetivo a justificação de cortes e mudanças na educação, apesar de a grande motivação das reformas do ensino ser sempre a de utilizar a educação para a defesa dos ideais do Estado, como ferramenta de propagação dos pensamentos absolutistas e como meio de submissão ideológica (Aguiar 2014, 50).

A 6 de julho de 1936, "uma comissão encarregada de colaborar na reforma das secções de música e de teatro do Conservatório Nacional (...) é nomeada por portaria inserta no Diário do Governo n. ${ }^{\circ}$ 155, II. ' Série" (Gomes 2002, 143). No ano seguinte, em 1937, a mesma comissão, com Vianna da Motta como presidente, concebeu o documento "Bases para um projecto de reorganização do Conservatório Nacional apresentadas pela Comissão nomeada 
por Sua Excelência o Senhor Ministro da Educação Nacional." Ivo Cruz, que em 1938 se torna o novo diretor da Escola de Música do Conservatório Nacional, envida esforços no sentido de alcançar as necessárias reformas do ensino artístico. Apresenta três propostas, a última em 1966, elaborada pelos professores do Conservatório Nacional; porém, apesar de toda a sua determinação, nenhuma alteração foi realmente conseguida até à publicação do Decreto-Lei $n^{\circ} 310$ a 1 de julho de $1983^{8}$. De acordo com Palheiros (1993),

[o] modelo curricular definido pelo decreto de 1930, praticado pelo Conservatório Nacional e adoptado pelas escolas de música públicas, particulares e cooperativas [...] viria a cristalizar, durante mais de cinco décadas, o ensino vocacional da música em Portugal. (40)

Embora, após a elaboração da proposta de reforma de 1966, apenas tivesse obtido silêncio como resposta, Ivo Cruz não se deixou intimidar com a repressão exercida pelo governo, desenvolvendo um plano de renovação do sistema de ensino de música. Tendo como referência o que era praticado noutros países europeus, considerou essencial reestruturar não só a estrutura curricular, mas também o cuidado com as infraestruturas, designadamente no que se refere à reabilitação das instalações.

São dignas de nota as actividades levadas a efeito quer por professores, quer por alunos, nomeadamente: os recitais da Nova Geração; os concertos do Collegium Musicum e os de intercâmbio com diversas escolas do país; a realização de cursos e conferências da responsabilidade de eruditos, nacionais e/ou estrangeiros, que se destacam no panorama musical; a promoção do estudo de instrumentos antigos. (Aguiar 2007, 33)

Em termos culturais, a grande maioria dos acontecimentos musicais eruditos circunscreviam-se a Lisboa. O resto do país mergulhava no esquecimento, salvo iniciativas pontuais de prática coral em algumas coletividades. O programa do Teatro de São Carlos era sempre verificado pelo poder, de modo a garantir que o objetivo primordial era assegurado: a valorização e a promoção do Estado. Como sublinha Mário Vieira de Carvalho (1993), "o que importava aparentar era que o regime não estava demasiado isolado dos intelectuais" (236). O regime mantinha sempre uma distância considerável de todos os programas culturais e artísticos que não eram da sua responsabilidade, quer fossem produções portuguesas ou estrangeiras, receando que estes pudessem vir a difundir propaganda antirregime. Consequentemente, e na ótica de Brito e Cymbron (1992, 169), aos poucos, o país ia-se isolando das correntes culturais e artísticas que proliferavam na Europa.

O canto coral, com a sua capacidade única de aliar música e texto, logo se tornou no veículo privilegiado de divulgação e promoção das ideias do regime do Estado Novo. A vertente estética da música, e o lado educativo da mensagem, constituíam um meio de aproximação entre pessoas de diferente estatuto social e de partilha de ideais políticos. Não obstante, Lopes-Graça (1973) alertava que,

em Portugal, as crianças e os jovens não cantavam praticamente, desconheciam, eles e quem cuidava da sua educação, os benefícios de ordem vária - artísticos, físicos, psicológicos, morais - que decorrem desse acto, no fundo tão simples, tão natural e tão humano, que é o cantar em comum. (117) 
Dotado de um grande sentido de perseverança, Tomás Borba insistia na utilização de novos métodos de pedagogia musical (solfejo entoado e ginástica rítmica), conseguindo que a disciplina de Canto Coral passasse a ser prevista nos currículos escolares, e que viesse a ser aprovado um regulamento de Canto Coral nos liceus. Através destas aulas de canto coletivo, procurava contribuir-se para uma sociedade mais solidária, almejando uma formação moral e cívica dos coralistas; acreditava-se possível educar esteticamente os cidadãos e sem o objetivo concreto de formar artistas (embora fossem também ministradas algumas noções básicas de música). Neste sentido, Tomás Borba compôs, propositadamente, obras que possibilitassem a prática coral, em colaboração com escritores portugueses, nomeadamente Adolfo Portela e Afonso Lopes Vieira. As obras O Canto Coral nas Escolas (em quatro volumes) e Toadas da Nossa Terra, que foram publicadas no início do século XX, foram difundidas e trabalhadas nas escolas, contribuindo para que o canto coral fosse sobrevivendo às sucessivas alterações do sistema de ensino.

Relativamente ao repertório que se escutava nas festas educativas dos liceus, Barreiros (1999) refere o ano letivo de 1933/1934, em que se executaram algumas canções dos compositores Josué Trocado e Tomás Borba, estendendo-se o repertório a canções do compositor Armando Leça ("Velas ao Alto" e "Anda a Roda") e do professor de História da Música, Hermínio do Nascimento ("As Amendoeiras" e "A Moleirinha"). Ouviram-se ainda algumas canções populares, canções francesas e canções animadas ("Barcarola", "O Gato e o Rato" e "Armas de Cana") (Barreiros 1999, 110).

Contrariamente às expectativas, o movimento coral em Portugal, aos poucos, começou a ganhar simpatizantes. Sem ligação à obrigatoriedade patente no sistema educativo, são criados diversos grupos corais, embora muitos deles interpretassem repertórios circunscritos às diretivas propagandísticas do Estado e de qualidade questionável. De acordo com Barreiros (1999), o "texto e a música nem sempre se ajustam de uma forma clara e bem ritmada, de que resulta uma linha melódica pouco fluente e uma compreensão do texto confusa" (108). O ideal de Tomás Borba relativamente ao carácter formativo ficava comprometido, bem como a preparação técnica dos coros, que praticamente não existia.

Um dos coros que se destacou como excepção foi, sem dúvida alguma, o Coro da Academia de Amadores de Música, orientado por Fernando Lopes-Graça. Para além de harmonizações de canções regionais, Lopes-Graça compôs canções de luta, de convívio, cuja finalidade era serem cantadas pela população, como forma de protesto contra o Regime. Com a consciência plena de que o fascismo era transitório e que a sua música permaneceria, continuava activo na sua luta exprimindo-se através dos meios vocais e instrumentais. (Aguiar 2007, 43)

Em 1936 é criada uma associação nacional de aproveitamento dos tempos livres de crianças e jovens. Surge, assim, a Mocidade Portuguesa e, um ano mais tarde, a Mocidade Portuguesa Feminina. Estas organizações oficiais de juventude eram parte integrante do Ministério da Educação Nacional e o seu principal propósito prendia-se com a formação dos mais jovens, sempre em conformidade com os valores defendidos pelo regime. A Mocidade Portuguesa passava, assim, a agregar todas as associações juvenis, bem como os serviços de música e o canto coral. Como certamente se compreenderá, esta medida veio a gerar alguma controvérsia entre os liceus e a Mocidade Portuguesa. 
Mau grado estas polémicas, o canto coral obteve meios e possibilidades de se desenvolver, acabando, contudo, por se submeter

à crescente ideologização do regime. A intenção [do Canto Coral vir a cumprir] [...] uma função educativa é subvalorizada pela tutela que, por essa razão, nunca chega a criar as condições institucionais necessárias à sua real participação e contributo no currículo liceal. (Barreiros 1999, 127- 128)

É gradual a aceitação do canto nas atividades sociais, mas o trabalho vocal é quase sempre preterido em favor do cuidado a ter com a transmissão da mensagem do texto, meio difusor do sentido patriótico de união da nação. Veículo mobilizador das camadas jovens, o movimento coral deveria exibir a imagem de uma sociedade estruturada e exemplar. Segundo Graça Boal Palheiros (1993), esta atitude contribuiu para a

má memória que várias gerações têm dessas penosas aulas de Canto Coral, cujo conteúdo não era, certamente, muito motivador para os alunos: o hino nacional; algumas canções especialmente compostas com a intenção de suscitar pensamentos patrióticos; outras canções com um valor estético e musical bastante duvidoso. A monotonia dessas aulas, aliada a um ensino de carácter repressivo e inibidor da expressão, nomeadamente vocal, poderão ter contribuído para criar uma certa timidez perante a perspectiva de cantar, que muitos portugueses revelam. (28)

É na década de sessenta que mais se faz sentir o descontentamento com as imposições do Estado, começando a generalizar-se as revoltas estudantis, apoiadas, bastas vezes, por publicações clandestinas. Surgem algumas iniciativas de contestação através das peças de teatro do Círculo de Iniciação Teatral da Academia de Coimbra (CITAC), e o próprio fado de Coimbra vem a adotar um papel de caráter interventivo (destacam-se os nomes de José "Zeca" Afonso e Adriano Correia de Oliveira). Apesar de todas estas tentativas de oposição ao governo, a ordem e a disciplina determinadas pelo Estado Novo eram asseguradas, num país em que a cultura se encontrava estagnada, em que a escola assegurava as suas funções pedagógicas e de formação do caráter dos jovens, e em que a prática da religião católica e a exaltação da pátria eram pilares incontornáveis; imperava a máxima “Deus, Pátria e Família".

Lajes e Reis $(2006,4)$ dão destaque à ação desenvolvida pela Fundação Calouste Gulbenkian, designadamente na organização de determinadas iniciativas privadas e mesmo oficiais, e na promoção de cursos de pedagogia musical ativa, promovidos por vários pedagogos, incluindo Orff, Willems, Kodály, que se dedicaram

à procura de modelos de ensino/aprendizagem da Música que estimulassem o interesse dos alunos e contribuíssem para a sua expansão social e cultural. A todos eles se pode atribuir o mérito da reforma do ensino desta arte, a partir da segunda metade do século XX. (Soares 2012, 29-30) 
Maria Madalena Perdigão tornou-se a primeira diretora do serviço de música da Fundação Calouste Gulbenkian, em 1958, e assumiu um papel de destaque, sendo responsável por novas abordagens pedagógicas ao nível da educação e pela afirmação da atividade musical daquela fundação no panorama musical português e internacional, levando à criação de agrupamentos artísticos permanentes: a orquestra (1962), o coro (1964) e o ballet (1965).

Poucas mais iniciativas foram realizadas com sucesso ao longo do período de vigência do Estado Novo. Todas as diligências concretizadas, quer em termos educativos, quer em termos culturais, contribuiriam para a consolidação do sentimento de União Nacional, mediante a homogeneização de organizações, conhecimentos, princípios e condutas.

\section{O ENSINO DA MÚSICA ATRAVÉS DOS MEIOS DE FORMAÇÃO À DISTÂNCIA NA DÉCADA DE CINQUENTA: A RÁDIO ESCOLAR E A TELESCOLA}

Na década de cinquenta, devido à urgência em minorar o atraso do sistema educativo português, é levada a efeito uma iniciativa de âmbito educativo com o objetivo de aproximar o ensino formal da educação à distância. Foram criados os serviços da rádio escolar, sob a alçada da Direção Geral do Ensino Primário, contribuindo para uma maior facilidade na difusão da informação e no divulgar dos programas de ensino, promovendo a celeridade da formação em geral. A ideia não era substituir as aulas por emissões da rádio escolar; pretendia-se chegar mais longe e a um maior número de pessoas, complementando o ensino com diferentes metodologias. Tendo em conta os programas oficiais das disciplinas, a programação das sessões musicais radiofónicas procurava simplificar a linguagem utilizada na transmissão de conteúdos, numa tentativa de auxiliar os professores com mais dificuldades, realizando um ensino de caráter abrangente e globalizante.

Segundo Dias (2009, 157), os programas radiofónicos obedeciam a um conceito de ensino integrado: eram divididos em emissões-lições que se organizavam segundo as disposições curriculares das disciplinas. As emissões tinham transmissão semanal, e a emissão-lição de educação musical era alternada com as outras disciplinas escolares. De acordo com o estudo realizado pela investigadora,

documentados os serviços, estudadas as experiências e actividades radiofónicas de outros países, adaptados e inovados os programas das Escolas do Magistério a Direcção Geral do Ensino Primário deu início no final da década de cinquenta, à fase experimental do alargamento das actividades de Rádio Escolar, com enfoque particular sobre a disciplina de educação musical. (Dias 2009, 157)

Na programação da rádio escolar transmitida ao longo do ano letivo 1960/1961, destacam-se disciplinas como Música e Educação Musical. Curiosamente, o número de programas exibidos ultrapassava os de História, Geografia, Língua Materna e Ciências Naturais; por outro lado, o Canto Coral surgia apenas com a previsão de quatro programas, número de emissões estranhamente superior ao de Geografia e de Ciências Naturais. 
Por esta altura surgiam em Portugal novas metodologias da educação musical assentes em novas bases filosófico-psicológicas; nomes de grandes pedagogos como Carl Orff, Émile Jaques-Dalcroze, Zoltán Kodály e Edgar Willems passam a fazer parte do sistema de ensino. A pedagogia de Willems, propondo a execução de tarefas e exercícios assentes numa pedagogia musical ativa em que a escuta e o trabalho auditivo constituem o suporte de toda a educação musical, viria a ter grande aceitação no país. Relativamente ao ensino à distância, a programação radiofónica opta por um formato tripartido da emissão que compreende canto coral, música e educação musical. Segundo Dias (2009), com base

nas novas pedagogias musicais, revelando forte influência das teorias psicológicas de Edgard Willems e da pedagogia musical de Orff-Schulwerk [...] a programação [...] [do] Canto coral [...] intentava encontrar formas do agradar às crianças, divulgando canções populares acessíveis às crianças e aos professores ajudando-os a exercitar os alunos na prática do canto em coro. Juntava ao esse repertório de canções populares, as de recreio e de exercício, de duas a cinco notas de intervalos e rítmicas, a fim de despertar o sentido artístico. (Dias 2009, 158-159)

De acordo com a mesma autora, os programas de educação musical tinham como objetivo a divulgação das novas metodologias musicais, promovendo, junto dos alunos, por meio de canções, os conhecimentos integrantes de diferentes domínios, designadamente, ordenações musicais, ritmo e improvisação. Por sua vez, os programas de música visavam à formação de ouvintes, desenvolvendo a sensibilidade e o sentido estético, contribuindo para o desenvolvimento cultural do país, à semelhança de outros países mais desenvolvidos (Dias 2009, 159).

O funcionamento deste ensino era monitorizado. Se antes da sessão radiofónica era elaborado o "Boletim de Orientação", a seguir à mesma completava-se o "Boletim de Escuta", como processo de avaliação. O primeiro assumia um caráter de planificação da emissão, com três parâmetros obrigatórios: antes, durante e depois da sessão; por sua vez, o "Boletim de Escuta" consistia numa ferramenta de controlo e avaliação, quer do programa em si, quer do processo de ensino-aprendizagem, diagnosticando pontos fortes e débeis daquela emissão específica. Atente-se, como exemplo, ao final do ano letivo de 1961/1962, em que, com base nesses momentos de avaliação contínua do projeto das emissões radiofónicas, foi feito o balanço de todo o percurso, estimando também o nível de satisfação dos intervenientes. Desta forma, devido a uma avaliação negativa do programa de música, a emissão ficou reduzida ao canto coral e à educação musical.

O preenchimento e devolução de ambos os boletins era obrigatória. Tudo era controlado de forma minuciosa, garantindo, assim, uma efetiva supervisão do trabalho dos professores e levando a uma normalização de todas as atividades. Deste modo, e em tempo útil, tornavam-se possíveis intervenções para reformulação das atividades planificadas, bem como das próprias sessões-aula transmitidas. Concomitantemente, acrescenta Dias (2009),

o Boletim mantinha o controlo do professorado, a orientação estético-pedagógica da própria disciplina e em última análise, disciplinava o discurso sobre a experiência radiofónica. (161)

A revista Escola Portuguesa surge como meio de comunicação entre professores e escolas, bem como destes e da própria organização do projeto radiofónico. Numa partilha de resultados, os Boletins de Orientação e de Escuta eram dados a conhecer à comunidade 
educativa através da sua divulgação na revista, que cedo se tornou num espaço de publicação de artigos e de depoimentos para formação pedagógica dos professores.

A crença nos benefícios do ensino à distância levou ao despontar da Telescola, a par com o nascimento das primeiras emissões da Radiotelevisão Portuguesa.

A 31 de dezembro de 1964, é criada pelo Decreto-Lei nº 46136 no Ministério da Educação Nacional, na dependência do Instituto de Meios Áudio-Visuais de Ensino, uma Telescola destinada à realização de cursos de radiodifusão e televisão escolares e, no ano seguinte, a 17 de fevereiro, através da Portaria $n^{\circ} 21114$ do Ministério de Educação Nacional, o mesmo Instituto passa a integrar quer Telescola, quer a Rádio Escolar. (Aguiar 2014, 59)

O sistema de ensino via televisão, Curso Unificado Telescola, é iniciado em Portugal a 6 de janeiro de 1965 nos estúdios da Radiotelevisão Portuguesa do Monte da Virgem, no Porto. Nas salas de aula havia postos de receção e os alunos eram acompanhados por monitores enquanto visualizavam as sessões. O ensino dividia-se entre os professores, que preparavam e gravavam as sessões, e os monitores, que acompanhavam os alunos e clarificavam as suas dúvidas. Era também da responsabilidade dos professores a preparação de toda a documentação de apoio aos monitores e aos alunos (Boletim de Orientação de Monitores e Manuais do aluno).

De acordo com Almeida e Matos (2011),

ao Sábado, eram emitidas lições das disciplinas de Canto Coral, Religião e Moral, Desenho e Educação Física. As lições de Educação Física e Canto Coral ocupavam 25 minutos e não dispunham de exploração imediata; para Religião e Moral também não havia exploração imediata. (74)

Pouco se sabe acerca do modo como decorriam estas sessões televisivas de Canto Coral; contudo, este tipo de ensino prolongou-se por diversos anos, tendo as autoras deste artigo assistido a algumas sessões nos finais dos anos 70, que se centravam, sobretudo, em questões de "gramática musical" ou funcionamento da linguagem musical, mais do que em repertório específico. Não obstante, eram frequentes as sessões de formação para os monitores, visando todos os conteúdos ministrados pelo professor da televisão, permitindo a sua atualização para uma melhor exploração e consolidação das matérias em sala de aula.

Nunca se propondo como alternativa, mas como complemento, os programas das disciplinas transmitidas pela Rádio Escolar e pela Telescola eram os mesmos do ensino regular, não mediatizado. Segundo Almeida e Matos,

[f]oram, fundamentalmente, razões de ordem política as que levaram à criação deste sistema de ensino misto, isto é, a necessidade de diminuir as grandes assimetrias no desenvolvimento regional e de colmatar lacunas na rede escolar. (Almeida e Matos 2011, 71)

A Telescola, tal como a Rádio Escolar, servia principalmente as zonas rurais isoladas, levando o conhecimento aos pontos mais escondidos e afastados dos centros urbanos. Embora destinadas à comunidade escolar, as emissões eram acessíveis a toda a população através de um monitor de televisão ou de um aparelho de rádio. 


\section{CONCLUSÃO}

Em suma, na primeira metade do século XX, não fosse a sua condição de submissão aos interesses políticos, e de subserviência ao regime do Estado Novo, o Canto Coral poderia ter assumido um lugar de destaque no desenvolvimento pedagógico-musical português. A sua história desenrola-se numa perspetiva mais utilitária do que formativa e educacional. Embora de valor reconhecido, quer no período da Primeira República, quer durante os longos anos da ditadura que the sucedeu, o Canto Coral foi sempre posto ao serviço do regime, ora propagandeando os ideais republicanos, ora divulgando os do Estado Novo, divulgando os princípios doutrinários da pátria e reforçando a vertente de cariz nacionalista. São prova disso os textos da legislação vigente nas épocas referidas.

O Decreto $n^{\circ} 4799$ de 8 setembro de 1918, publicado no Diário do Governo, $1^{\text {a }}$ Série, de 12 de setembro, $n^{\circ} 198$, que aprova o regulamento da instrução secundária ${ }^{9}$, advoga que as canções devem estar em conformidade com a idade dos alunos "segundo o tríplice critério da moral, da beleza e do sentimento nacionalista [...] e preferindo, dentro destas normas, aquelas que tenham carácter nacional" (1656).

Anos mais tarde, em 1936, António Faria Carneiro Pacheco toma posse da pasta da Instrução Pública. A 11 de abril do mesmo ano, é publicada a Lei $n^{\circ} 1941$, que procede à remodelação do Ministério de Instrução Pública ${ }^{10}$, o qual passa a designar-se Ministério da Educação Nacional. Na Base XII da mesma lei pode ler-se que o canto coral será obrigatório "como elemento de educação e de Coesão Nacional" e que será organizada

uma pequena colecção de cânticos nacionais, exaltando as glórias portuguesas, a dignidade do trabalho e o amor Pátria, os quais serão freqüentemente executados e constituïrão a base de um programa, sempre pronto, para as festas escolares, assim como para as grandes expressões do sentimento nacional. (Base XII da Lei n 1941 de 11 de abril de 1916)

De acordo com Maria José Barreiros, investigadora que se dedicou ao estudo da disciplina de canto coral no período do Estado Novo,

assiste-se ao que João Formosinho chamou de fase de mobilização do regime, para a qual se esperava que o Canto Coral desse uma importante contribuição. A acção da disciplina devia ultrapassar o âmbito do indivíduo (educação da pessoa) para alcançar o todo social (no sentido de educação colectiva). (Barreiros 1999, 70)

Ao longo da sua evolução, o movimento do coral sofreu sempre influência do poder político, quer da Primeira República, quer do regime do Estado Novo. Ainda que diversos pedagogos empreendessem tentativas meritórias para a sua valorização, destacando todas as suas virtudes como área formativa e enquanto disciplina curricular, a sua sujeição aos padrões ideológicos do Estado condenou-o ao servilismo do regime ditatorial português. 


\section{NOTAS}

1 Decreto de 30 de março de 1911 publicado no Diário do Governo No. 73.

2 Decreto com força de lei, publicado no Diário do Governo de 26 de maio de 1911.

3 Decreto 5787-A de 10 de maio de 1919, publicado no Diário do Governo n 98

4 Decreto n 1637, de 11 de junho de 1915, publicado no Diário do Governo n 110.

5 Decreto n 4650 de 14 de julho de 1918, publicado no Diário do Governo n 157.

6 Decreto n 18461 de 14 de junho de 1930, publicado no Diário do Governo n. 136.

7 Decreto n 18881 de 25 de setembro 1930, publicado no Diário do Governo n 223.

8 Decreto-Lei n 310/83 de 1 de julho de 1983, publicado no Diário da República nº 149

9 Decreto n 4799 de 8 de setembro de 1918, publicado no Diário do Governo nº 198.

10 Lei nº 1941 de 11 de abril de 1936, publicada no Diário do Governo nº 84.

\section{REFERÊNCIAS}

Aguiar, Maria Cristina. 2007. “O Ensino de Canto em Portugal: uma perspectiva analítico-reflexiva a partir de meados do Século XX". Tese de Mestrado, Universidade de Aveiro, Portugal.

—. 2014. "O ensino de Canto no $1^{\circ}$ Ciclo do Ensino Básico, nos ramos genérico e vocacional. Um estudo de caso múltiplo". Tese de Doutoramento, Universidade do Minho, Portugal.

Almeida, Mária, e José Matos. 2011. “Modelando um novo currículo - a Matemática Moderna no início da Telescola". Em Actas do I Congresso Ibero-Americano de História da Educação Matemática, editado por José Manuel Matos e Manuel Saraiva, 69-84. Lisboa, Portugal: Várzea da Rainha Impressores SA.

Barreiros, Maria José. 1999. "A disciplina de Canto Coral no período do Estado Novo: contributo para a história do ensino da educação musical em Portugal." Tese de Mestrado, Universidade Nova de Lisboa, Portugal.

Brito, Manuel, e Luísa Cymbrom. 1992. História da música portuguesa. Lisboa: Universidade Aberta.

Carvalho, Mário. 1993. Pensar é morrer ou oTeatro de São Carlos na mudança de sistemas sociocomonicativos desde fins do século XVIII aos nossos dias. Lisboa: Imprensa Nacional-Casa da Moeda.

Carvalho, Rómulo. 1986. História do ensino em Portugal. Desde a fundação da nacionalidade até o fim do regime de Salazar-Caetano. Lisboa: Fundação Calouste Gulbenkian.

Correia, Luís. 2010. "Centenário da República: O ensino primário na primeira república - O homem vale, sobretudo, pela educação que possui". Revista Seara Nova. http://www.searanova.publ.pt/pt/1713/ dossier/163/Centen\%C3\%A1rio-da-Rep\%C3\%B. (Acesso 7 de março de 2012).

Cunha, Maria Helena. 2002. O ensino secundário liceal na Primeira República. Millenium, 26: 226-254.

Decreto com força de lei, publicado no Diário do Governo de 26 de maio de 1911, que cria e regulamenta a Instrução Militar Preparatória.

Decreto de 30 de março de 1911, publicada no Diário do Governo n 73, que cria o ensino infantil público e reformula as bases do ensino primário. 
Decreto n 1637, de 11 de junho de 1915, publicado no Diário do Governo n 110, que cria um curso especial de educação feminina.

Decreto n 4650 de 14 de julho de 1918, publicado no Diário do Governo n 157, que reforma os serviços da Instrução Secundária.

Decreto n 4799 de 8 de setembro de 1918, publicado no Diário do Governo n 198, que aprova o regulamento da Instrução Secundária.

Decreto $n^{\circ}$ 5787-A de 10 de maio de 1919, publicada no Diário do Governo n 98, que reforma o ensino primário.

Decreto $n^{\circ} 18461$ de 14 de junho de 1930, publicado no Diário do Governo n 136, que determina que o Conservatório Nacional de Música e o Conservatório Nacional de Teatro passem a constituir uma instituição escolar única denominada Conservatório Nacional.

Decreto $n^{\circ} 18881$ de 25 de setembro 1930, publicado no Diário do Governo $n^{\circ}$ 223, que aprova a reorganização do Conservatório Nacional.

Decreto-Lei n 310/83 de 1 de julho de 1983, publicado no Diário da República n 149, que reestrutura o ensino da música, dança, teatro e cinema.

Dias, Maria Anjos. 2009. “Para uma genealogia da educação artística. História das disciplinas de Desenho, Trabalhos Manuais, Canto Coral e Educação pelo Teatro na escola primária portuguesa, do primeiro quartel do século XIX a meados do século XX". Tese de Doutoramento, Universidade do Minho, Portugal.

Lajes, Maria Alcina, e Sofia Reis. 2006. "Contribuição para a investigação em ciências da educação: as actas dos colóquios da AFIRSE/AIPELF revisitadas."Em Actas do XIV Colóquio da AFIRSE: 1-21. http://www.afirse.com/archives/cd7/Textos \% 20Actas \% 20Afirse \% 202006/Ateliers/TMI/TMI1/ TMI1_Lajes_all.pdf. (Acesso 6 de março de 2018).

Lei n 1941 de 1 de abril de 1936, publicada no Diário do Governo n 84, que procede à remodelação do Ministério de Instrução Pública.

Lopes-Graça, Fernando. 1973. A música portuguesa e os seus problemas III. Lisboa: Edições Cosmos.

Nery, Rui e Paulo Castro. 1991. História da música. Lisboa: Imprensa Nacional-Casa da Moeda.

Palheiros, Graça. 1993. Educação musical no ensino preparatório. Uma avaliação do currículo. Lisboa: APEM.

Pimenta, Paulo. 2006. "A escola portuguesa. Do 'Plano dos Centenários' à construção da rede escolar no distrito de Vila Real.'Tese de Mestrado, Universidade do Minho, Portugal.

Reis, António, Ana Magalhães, e Isabel Alçada. 2010. O 5 de Outubro e a Primeira República. Alfragide: Editorial Caminho.

Rocha, Filipe. 1984. Fins e objectivos do sistema escolar português. I. Período de 1820 a 1826. Porto: Paisagem Editora.

Soares, Dina. 2012. "O ensino da Música no $1^{\circ}$ Ciclo do Ensino Básico: das orientações da tutela à prática lectiva". Dissertação de Mestrado, Universidade de Coimbra, Portugal.

\section{Cómo citar:}

Aguiar, Maria Cristina y Maria Helena Vieira. 2018. “O movimento do Canto Coral no sistema educativo português da Primeira República ao Estado Novo." Cuadernos de Música, Artes Visuales y Artes Escénicas 13 (2): 189-204. http://doi.org/10.11144/javeriana.mavae13-2.omdc 